\title{
The Relationship Between Emotional Self-efficacy, Sensation Seeking, and the Quality of Child-Parent Relationships With Quality of Life Mediated by High-Risk Sexual Behaviors in Students
}

\author{
Farnoosh Sadat Etminan $^{1 \oplus}$, Kobra Haji Alizadeh ${ }^{1 * \circledast}$, Seyed Abdul Wahab Samavi ${ }^{2}$ \\ ${ }^{1}$ Department of Psychology, Bandar Abbas Branch, Islamic Azad University, Bandar Abbas, Iran \\ ${ }^{2}$ Department of Educational Sciences, Faculty of Humanities Sciences, University of Hormozgan, Bandar Abbas, Iran
}

\begin{abstract}
Background: Considering the importance of quality of life which is related to various physical, psychological, social, and political dimensions of the individual and the importance of the class which plays a decisive role in forming a successful and healthy society. Also, considering the importance of high-risk behaviors in today's society and the harm that these behaviors create, five variables of quality of life, type of parent-child relationship and sensation seeking, self-efficacy, and high-risk sexual behaviors have been studied together.

Methods: The research method was descriptive-correlational with structural equation modeling (SEM). The statistical population included all male and female undergraduate students of Bandar Abbas Branch of Azad University who were studying in the first semester of the 2018-2019 academic year. 260 people were selected through purposive sampling. The inclusion criteria were being an undergraduate student, conscious satisfaction with the implementation method and research process. Data were gathered by the Child-Parent Relationship Quality Questionnaire (PCRS), Zuckerman Sensation Seeking Scale, Quality of Life Questionnaire, High-Risk Sexual Behaviors Questionnaire and Emotional Self-efficacy Scale. Data were analyzed using structural equations with Amos software, version 8.80 .

Results: The path coefficient between high-risk sexual behaviors and quality of life was -0.84 , which indicates the negative and inverse effect of high-risk sexual behaviors and quality of life. The path coefficient between the quality of the parent-child relationship and high-risk sexual behaviors was -0.86 , which indicates the negative and inverse effect of the quality of the parent-child relationship and high-risk sexual behaviors.

Conclusion: High-risk sexual behaviors mediate the quality of the parent-child relationship and the quality of life of students.

Keywords: Emotional self-efficacy, Sensation seeking, Child-parent relationship, Quality of life, Sexual behaviors
\end{abstract}

\author{
*Correspondence to \\ Kobra Haji Alizadeh, \\ Department of Psychology, \\ Bandar Abbas Branch, Islamic \\ Azad University, Bandar Abbas, \\ Iran. \\ Tel: +9876-33665500; \\ Email:Ph_alizadeh@yahoo.
}

com

Published online March 27, 2021

Citation: Etminan FS, Alizadeh K, Samavi SAV. The relationship between emotional self-efficacy, sensation seeking, and the quality of child-parent relationships with quality of life mediated by high-risk sexual behaviors in students. Clin Neurosci J. 2021;8(2):90-95. doi:10.34172/icnj.2021.19.

\section{Introduction}

According to the definition of the World Health Organization (WHO), quality of life is the perception that individuals have of their life status, cultural background, and value systems in which they live, their goals, expectations, standards, and priorities. Students' quality of life is generally related to the circumstances in which they live. ${ }^{1}$ The family is one of the most central educational environments that affects the maintenance of mental, physical and social health. The psychological conditions of the family and the quality of emotional relationships between parents and children have a great impact on creating adjustment and mental health, developing social skills and improving the quality of life of children. ${ }^{2}$ In this regard, there is a significant relationship between parentchild relationship style and quality of life in adulthood. ${ }^{3}$ One of the important factors that improve the quality of life of students is emotional self-efficacy. ${ }^{4}$ Emotional selfefficacy is a set of behavioral preparations and desires of the individual in recognizing, processing, and organizing emotional information. ${ }^{4}$ It increases self-efficacy, personal health, the ability to do homework in many ways and it makes people see homework as a challenge that they have to master, they are confident that they can

(C) 2021 The Author(s). This is an open access article distributed under the terms of the Creative Commons Attribution License (http:// creativecommons.org/licenses/by/4.0/), which permits unrestricted use, distribution, and reproduction in any medium, provided the original work is properly cited. 
contain potential threats and adapt well to the situation, as a result, they experience a higher quality of life. ${ }^{5}$ In this regard, the results of one study showed that self-efficacy significantly predicts quality of life. ${ }^{6}$

One of the factors that can affect the quality of life of students is sensation seeking. ${ }^{7}$ Fardis defines sensation seeking as the desire for "diverse emotions and experiences, and a strong tendency to take physical, social, legal and financial risks because of such an experience. ${ }^{8}$ Zuckerman identified four elements of sensation seeking using factor analysis: thrill and adventure seeking, disinhibition, experience seeking, and boredom susceptibility. ${ }^{9}$ On the one hand, people's sensation seeking increases their risk-taking to gain pleasure, so that they take actions for pleasure and eliminate monotony, which reduces their mental health and quality of life, and on the other hand, they ignore or underestimate the dangers and negative consequences of tending to high-risk behaviors.?

Quality of life is a multidimensional structure that cannot be studied in a simple linear structure, so in the present study, high-risk sexual behavior is considered as a mediating variable. High-risk sexual behaviors are divided into two areas: (1) Definitions of sexual behavior that include high-risk, moderate-risk, safe and secure, and in general these behaviors have different degrees of risk, (2) Definitions of the type of sex that includes the primary sexual partner and the secondary sexual partner. ${ }^{10}$ Some studies show parental communication and understanding also affect children's sexual behaviors. ${ }^{11}$ sensation seeking, on the other hand, increases the likelihood of high-risk behaviors by increasing the child's desire to experience new and varied events and accept physical and social risks. ${ }^{12}$ Self-efficacy, on the other hand, helps people use their ideas and thoughts to guide, motivate, and act toward their goals, resulting in less impulsivity and irrational behavior, High-risk behavior is less seen in selfefficient individuals. ${ }^{6}$

Assessing the quality of life of students and recognizing the factors related to it is important in the development of intervention programs and leisure programs of this group, which are the potential forces of the intellectual community. Therefore, we aimed to assess the relationship between emotional self-efficacy, emotion seeking and child-parent relationship quality with the quality of life of students mediated by high-risk sexual behaviors.

\section{Methods}

The present research was a correlational study using structural equation modeling (SEM). The statistical population were all male and female undergraduate students of Bandar Abbas Branch of Azad University who were studying in the first semester of the academic year 2018-2019 ( $\mathrm{n}=1365$ students). 260 students were selected as the sample by purposive sampling method. The sample size was selected according to Klein's rule. According to this rule, at least 20 samples are required for each parameter. According to the number of parameters of the present study (13 parameters), a minimum sample of 260 people was required. Data were gathered using the Child-Parent Relationship Quality Questionnaire (PCRS), Zuckerman Sensation Seeking Scale, Quality of Life Questionnaire, High-Risk Sexual Behaviors Questionnaire, and the Emotional self-efficacy scale. Before performing the study, all participants were informed and gave their consent to participate.

\section{Child-Parent Relationship Quality Questionnaire}

The PCRS is a 54-item tool for measuring young people's perceptions of their relationship with their parents. It has two forms, one for measuring the child's relationship with the mother and one for measuring the child's relationship with the father. This scale has alpha coefficients of 0.89 to 0.94 for father-related subscales as well as a total alpha of 0.96 and alpha coefficients of 0.61 (replication) to 0.94 for subscales related to the mother and a total alpha of 0.76 indicating a good internal consistency. These alpha coefficients were obtained in a previous study on 541 students. ${ }^{13}$

\section{Zuckerman Sensation Seeking Scale (1979)}

This scale was used to measure sensation seeking with four sub-factors of thrill and adventure seeking, disinhibition, experience seeking, and boredom susceptibility. This scale summarizes the fourth form of the Zuckerman Sensation Seeking Scale and consists of 40 two-part items. In each item, one of the two components expresses the amount of sensation seeking of the individual, and the second component is the opposite. The respondent gets a score for each question or item answered correctly, and a higher score indicates higher amounts of sensation seeking. Zuckerman and colleagues reported internal consistency of 0.83-0.86 for the scale subscales. ${ }^{9}$ Cronbach's alpha of the Persian version of this scale was $0.84 .{ }^{14}$

\section{Quality of Life Questionnaire}

This questionnaire was devised by the WHO in 1989 in collaboration with 15 international field centers. It consists of 26 items assessing four areas of physical health, psychological health, social relations and living environment and is used to measure the quality of life in the last two weeks. In the results reported by the WHO and the 15 international centers, Cronbach's alpha coefficient was reported to be $0.73-0.89$ for the four subscales and the whole scale. ${ }^{15}$ Cronbach's alpha of this scale in Hakimi Nia and colleagues' study was $0.82 .{ }^{16}$

\section{High-Risk Sexual Behaviors Questionnaire}

This questionnaire was designed by Zarie and colleagues. ${ }^{17}$ It has 10 items scored on a 5-point Likert scale from 1 (always) to 5 (never). In addition to demographic 
characteristics, this questionnaire contains 10 questions about illicit and insecure relationships with the opposite sex. The answers to the questionnaire are arranged in five choices and scoring is done from 1 to 5 points. (in the previous sentence you have mentioned 5 points) A higher score indicates a higher risk of engaging in highrisk sexual behaviors. To determine the content validity of the questionnaire, after preparing the questions based on the available background, 10 faculty members were asked for assistance. The validity coefficient was 0.68 using retesting after two weeks.

\section{Emotional Self-efficacy Scale}

The Emotional Self-Efficacy Questionnaire is a test with 32 questions developed by Schutte and co-workers (are you sure?) in 2008 and measures (diagnosis, comprehension, regulation and facilitation) on a 5-point Likert scale from a score of 1 to 5. Internal consistency of test questions was reported based on Cronbach's alpha coefficient of $0.96 .^{18}$ The retest validity coefficient in a sample of 27 people at a two-week interval was 0.85 . In one study Cronbach's alpha of this scale in the whole sample was $0.79 .{ }^{19}$

Data were analyzed using descriptive statistics such as mean and standard deviation using SPSS software, version 24. SEM was also done with AMOS software, version 25.

\section{Results}

The mean \pm SD age of the male and female students were $21.23 \pm 1.8$ and $20.3 \pm 1.9$, respectively.

In the method of structural equations and multivariate norms, normality is one of the important assumptions that must be considered. One of the common properties in examining the assumption of normality is the calculation of skewness and tensile statistics. The absolute value of the skewness coefficient is less than 3 and the kurtosis coefficient less than 10 for normality, and our data were within these ranges. The Durbin-Watson test was also used to check the independence of errors. The results showed that the assumption of independence was established and the observed values were between the allowed limit of 1.5 to 2.5 , which indicates that the errors are independent. A summary of the SEM results is presented in Table 1. According to the obtained indicators in the proposed model $\left(\chi^{2} / d f=2.785\right.$ GFI=0.918; IFI $=0.937 ;$ TLI $=0.943$; CFI $=0.921$ and $=0.059$ RMSEA), the model has a good fit. Direct and indirect paths of the model are shown in
Table 2.

As shown in Table 2, the path coefficient between highrisk sexual behaviors and quality of life was -0.84 , which indicates the negative and inverse effect of high-risk sexual behaviors on quality of life. The path coefficient between the quality of the parent-child relationship and high-risk sexual behaviors was -0.86 , which indicates the negative and inverse effect of the quality of the parent-child relationship and high-risk sexual behaviors. Moreover, high-risk sexual behaviors mediate the quality of the parent-child relationship and the quality of life of students. Therefore, the path coefficient between emotional selfefficacy and high-risk sexual behaviors was -0.79 , which indicates the negative and inverse effect of emotional selfefficacy and such behaviors. High-risk sexual behaviors mediate the relationship between emotional self-efficacy and students' quality of life. The path coefficient between arousal and high-risk sexual behaviors was -0.53 , which indicates the negative and inverse effect of arousal and high-risk sexual behaviors. Therefore, high-risk sexual behaviors mediate the relationship between students' sensation seeking and quality of life.

Considering the direct and indirect coefficients between the research variables, the final research model is presented in Figure 1, which indicates the mediating role of high-risk sexual behaviors in the relationship between emotional self-efficacy, sensation seeking and quality of child-parent relationships with quality of life in girl and boy students.

Table 2 presents the model fit indices in SEM. As can be seen, the research model has a good fit and the level of acceptance of the indicators has been met.

\section{Discussion}

The results of the present study showed that there was a significant relationship between the quality of the parentchild relationship and quality of life with the mediating role of high-risk sexual behaviors.

This finding is consistent with the findings of several other studies ${ }^{1,3,20}$ It can be said that it is the family and parents who transfer values, improve morals, and correct behavior. In fact, parents, as influential people in adolescents' lives, can help them get on the right track by using an authoritative parenting style and communicating effectively with them. They can improve their children's health-related behaviors by facilitating their emotional

Table 1. Goodness of Fit Indices of the Proposed Model

\begin{tabular}{lccccccc}
\hline & $\boldsymbol{P}$ value & $\boldsymbol{\chi} \mathbf{2}$ df & GFI & IFI & TLI & CFI & RMSEA \\
\hline Hypotheses & 0.417 & 2.785 & 0.918 & 0.937 & 0.943 & 0.921 & $>0.90$ \\
Appropriate level & $>0.005$ & $<5$ & $>0.90$ & $>0.90$ & $>0.90$ & $<0.1$ \\
Result & Suitable & Suitable & Suitable & Suitable & Suitable & Suitable \\
\hline
\end{tabular}

Abbreviations: GFI, goodness of fit index; IFI, incremental fit index; TLI, Tucker-Lewis index; CFI, comparative fit index; RMSEA, Root Mean Square Error of Approximation 
Table 2. Results of Structural Equation Modeling

\begin{tabular}{|c|c|c|c|c|c|c|c|}
\hline Relation & $\begin{array}{l}\text { The result of Examining } \\
\text { the Relationship } \\
\text { Between Variables }\end{array}$ & $\begin{array}{l}\text { Composite } \\
\text { Reliability } \\
\text { (CR) }\end{array}$ & $P$ Value & $\begin{array}{l}\text { Total } \\
\text { Effect }\end{array}$ & $\begin{array}{l}\text { Beta coefficient of } \\
\text { Indirect effect }\end{array}$ & $\begin{array}{c}\text { Beta } \\
\text { Coefficient of } \\
\text { Direct Effect }\end{array}$ & $\begin{array}{c}\text { Relationships of Research } \\
\text { Variables }\end{array}$ \\
\hline $\begin{array}{l}\text { Negative and inverse } \\
\text { and meaningful }\end{array}$ & Verification & 5.11 & $<0.001$ & -0.86 & - & -0.86 & $\begin{array}{l}\text { The quality of the parent-child } \\
\text { relationship and high-risk } \\
\text { sexual behaviors. }\end{array}$ \\
\hline $\begin{array}{l}\text { Positive and } \\
\text { meaningful }\end{array}$ & Verification & 5.89 & $<0.001$ & $\begin{array}{c}0.75 \\
-\end{array}$ & - & 0.75 & $\begin{array}{l}\text { Quality of parent-child } \\
\text { relationship and quality of life }\end{array}$ \\
\hline $\begin{array}{l}\text { Negative and inverse } \\
\text { and meaningful }\end{array}$ & Verification & 5.62 & $<0.001$ & -0.79 & - & -0.79 & $\begin{array}{l}\text { Emotional self-efficacy and } \\
\text { high-risk sexual behaviors }\end{array}$ \\
\hline Positive & Verification & 6.75 & $<0.001$ & 0.61 & - & 0.61 & $\begin{array}{c}\text { Emotional self-efficacy and } \\
\text { quality of life }\end{array}$ \\
\hline $\begin{array}{l}\text { Negative and inverse } \\
\text { and meaningful }\end{array}$ & Verification & 6.94 & $<0.001$ & -0.53 & - & -0.53 & $\begin{array}{l}\text { Sensation seeking and high- } \\
\text { risk sexual behaviors }\end{array}$ \\
\hline Positive & Verification & 6.37 & $<0.001$ & 0.51 & - & 0.51 & $\begin{array}{l}\text { Sensation seeking and quality } \\
\text { of life }\end{array}$ \\
\hline $\begin{array}{l}\text { Negative and inverse } \\
\text { and meaningful }\end{array}$ & Verification & 6.780 & $<0.001$ & -0.84 & - & -0.84 & $\begin{array}{l}\text { High-risk sexual behaviors and } \\
\text { quality of life of students }\end{array}$ \\
\hline Positive & Verification & 5.32 & $<0.001$ & 0.722 & $0.722-0.84 *-0.86$ & - & $\begin{array}{l}\text { Quality of parent-child } \\
\text { relationship - High-risk sexual } \\
\text { behaviors - Quality of life }\end{array}$ \\
\hline Positive & Verification & 5.13 & $<0.001$ & 0.663 & $0.663-0.84^{*}-0.79$ & - & $\begin{array}{l}\text { Emotional self-efficacy - High- } \\
\text { risk sexual behaviors - Quality } \\
\text { of life }\end{array}$ \\
\hline Positive & Verification & 5.79 & $<0.001$ & 0.445 & $0.445-0.84 *-0.53$ & - & $\begin{array}{c}\text { Sensation seeking - High-risk } \\
\text { sexual behaviors - Quality } \\
\text { of life }\end{array}$ \\
\hline
\end{tabular}

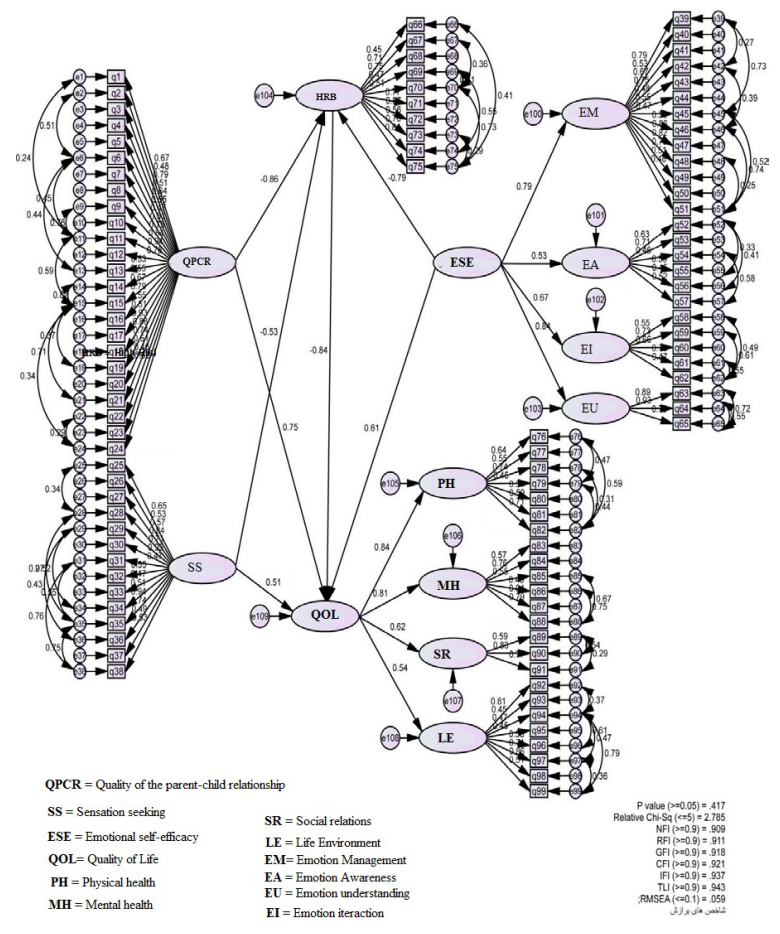

Figure 1. The Final Research Model. needs. Children with warm parents express their conflicts with them and ask for their guidance and help. Establishing a good relationship with parents leads to a sense of belonging in the child and adolescents internalize many patterns of social, cultural, and behavioral norms through assimilation to accepted patterns. By understanding the needs of the adolescent and responding appropriately, parents can become an acceptable model for children and by internalizing the rules and norms accepted by the society, prevent them from tending to risky behaviors. ${ }^{3}$

The results also showed that the path coefficient between emotional self-efficacy and quality of life was mediated by high-risk sexual behaviors. This finding is consistent with the findings of Foran et $\mathrm{al}^{2}{ }^{2}$ Beri et $\mathrm{al}^{4}$, and Izadi \& Barzegar $^{21}$ and their colleagues. To explain this, it can be said that self-efficacy increases the feeling of adequacy in adolescents and enables them to deal with their problems more effectively. ${ }^{2}$ Many high-risk behaviors of adolescents are related to their low self-esteem. In fact, self-efficacy prevents adolescents from feeling empty by increasing their self-esteem, which prevents many of their negative behaviors and leads to a better quality of life. Self-efficacy is the judgment of individuals about their ability to do a task or adapt to a particular situation..$^{22}$ Sometimes the 
lack of a sense of efficiency and inability to adapt to the environment in reality, leads adolescents to imaginatively satisfy these needs by committing high-risk behaviors such as substance abuse and alcohol and leads to reduced quality of life. ${ }^{4}$

We found that there was a significant relationship between sensation seeking and quality of life with the mediating role of high-risk sexual behaviors. This finding is in line with the findings of other researchers. ${ }^{7,10,12,23}$ People's sensation seeking on the one hand increases their risk-taking to gain pleasure, so that in order to gain pleasure and eliminate monotony, they take actions to improve their mental health and quality of life, but they ignore or underestimate the dangers and negative consequences of tending to risky behaviors. ${ }^{10}$

Also, the path coefficient between high-risk sexual behaviors and quality of life indicates the negative and inverse effect of high-risk sexual behaviors on quality of life. This finding is consistent with the findings of some other studies. ${ }^{24,25}$ In this regard, quality of life is an important factor that enables a person to positively balance life and avoid undesirable responses. People with better quality of life can face challenges of social life, cope with them and perform better in the society and be less prone to undesirable or anti-social behaviors. ${ }^{26}$

Therefore, considering the role of high-risk sexual habits in the relationship between emotional selfefficacy, sensation seeking and the quality of childparent relationships with quality of life, it is necessary that universities and counseling centers develop a special and suitable environment for the actual improvement of students' quality of life, to provide the ground for their further growth and prosperity.

Among the limitations of the present study are the limited sample of male and female undergraduate students of Bandar Abbas Branch of Azad University and the lack of control over some unwanted research variables. In this regard, the results of the present study should be generalized with caution.

\section{Conflict of Interest}

The authors declare that they have no conflict of interests.

\section{Acknowledgments}

This paper is extracted from the PhD. dissertation in General Psychology at the Islamic Azad University, Bandar Abbas Branch. We would like to thank all those who contributed to this research.

\section{Authors' Contribution}

FSE : gathered the information and wrote the original draft. $\mathrm{KH}$ : supervised the research, SAS: reviewed the manuscript and edited the manuscript and designed the figure.

\section{Funding/Support}

The present study has been supported by the Bandar Abbas Branch, Islamic Azad University, Bandar Abbas, Iran.

\section{Ethical Statement}

All ethical principles were considered in this study. The participants were informed about the purpose of the study and its implementation stages and signed the informed consent form. They were also assured about the confidentiality of their information, and were allowed to leave the study whenever they wished, and if desired, the findings of the study would be available to them.

\section{References}

1. Milic M, Gazibara T, Pekmezovic T, Kisic Tepavcevic D, Maric G, Popovic A, et al. Tobacco smoking and health-related quality of life among university students: mediating effect of depression. PLoS One. 2020;15(1):e0227042. doi: 10.1371/ journal.pone.0227042.

2. Foran HM, Fraude I, Kubb C, Wamboldt MZ. Assessment of the parent-child relationship. In: Wampler KS, McWey LM, eds. The Handbook of Systemic Family Therapy. Hoboken, NJ: Wiley-Blackwell; 2020. p. 35-54. doi: 10.1002/9781119788393.ch2.

3. Szkody E, Rogers MM, McKinney C. Risky sexual behavior: the indirect effects between parent-child relationship quality and quality of life in emerging adults. Qual Life Res. 2018;27(10):2639-45. doi: 10.1007/s11136-018-1919-z.

4. Beri N, Jain M. Personal growth initiative among undergraduate students: Influence of emotional self efficacy and general well being. Rupkatha J Interdiscip Stud Humanit. 2016;8(2):43-56. doi: 10.21659/rupkatha.v8n2.05.

5. Singh B, Udainiya R. Self-efficacy and well-being of adolescents. J Indian Acad Appl Psychol. 2009;35(2):227-32.

6. Yazdi-Ravandi S, Taslimi Z, Jamshidian N, Saberi H, Shams J, Haghparast A. Prediction of quality of life by self-efficacy, pain intensity and pain duration in patient with pain disorders. Basic Clin Neurosci. 2013;4(2):117-24.

7. Soleimani B, Rahimi A, Bayesti Z, Abolghasemi A. Investigating the relationship between happiness, quality of life and excitement with marital satisfaction. The First National Conference on Psychology and the Family; 2015. [Persian].

8. Fardis M. Expression and Regulation of Emotions in Romantic Relationships [dissertation]. Missoula, Montana: University of Montana; 2007.

9. Zuckerman M. Behavioral Expressions and Biosocial Bases of Sensation Seeking. New York: Cambridge University Press; 1994.

10. Shadkam S, Molazadeh J, Yavari A. Study of the mediating role of emotion regulation difficulties in the relationship between exposure to traumatic events and risky sexual behavior among substance abusers. Yafteh. 2016;18(3):78-87. [Persian].

11. Hosseinkhanzadeh AA, Taher M, Seyednuri SZ, Yahyazadeh A, Esapour M. Relationship between interaction parentchild with addictability rate and heterosexual orientation in students. Research on Addiction. 2014;7(28):59-74. [Persian].

12. Norbury A, Kurth-Nelson Z, Winston JS, Roiser JP, Husain M. Dopamine regulates approach-avoidance in human sensationseeking. Int J Neuropsychopharmacol. 2015;18(10):pyv041. doi: 10.1093/ijnp/pyv041.

13. Sanaei Zaker B. Family and Marriage Scales. Tehran: Besat Publication; 2019. [Persian].

14. Momeni K, Karami J, Hoveyzizadehgan N. The relationship between sensation seeking, positive and negative affect, alexithymia and marital infidelity. Journal of Health and Care. 2018;19(4):221-31. [Persian].

15. WHOQOL SRPB Group.A cross-cultural study of spirituality, 
religion, and personal beliefs as components of quality of life. Soc Sci Med. 2006;62(6):1486-97. doi: 10.1016/j. socscimed.2005.08.001.

16. Hakiminya B, Poorafkari N, Ghafari D. Factors affecting quality of life with emphasis on social intelligence and social health (the case of Kermanshah city). J Appl Sociol. 2017;28(2):16378. doi: 10.22108/jas.2018.74645.0. [Persian].

17. Zarie F, Khakbaz H, Karami H. Determining the effectiveness of self-awareness skill training on reducing high-risk behaviors associated with the opposite sex addict. Research on Addiction. 2010;4(15):63-70. [Persian].

18. Schutte NS, Malouff JM, Simunek M, McKenley J, Hollander S. Characteristic emotional intelligence and emotional well-being. Cogn Emot. 2002;16(6):769-85. doi: 10.1080/02699930143000482.

19. Souri A. Comparison of emotional self-efficacy, self-regulation learning strategies and motivational beliefs in privileged and non-privileged students. J Sch Psychol. 2020;9(3):101-19. doi: 10.22098/jsp.2020.1067.

20. Gorji R, Keshavarzi Arshadi F, Hatami M, Dehghan A, Vahabi R. A study of the relationship between parenting styles and risky behavior in deaf students. J Except Educ. 2015;4(132):512. [Persian].

21. Izadi A, Barzegar M. Investigating the relationship between emotional intelligence and quality of work life with self- efficacy of staff members of police headquarter commanders. J Resour Manag Police. 2017;(19):147-60. [Persian].

22. Yazdi-Ravandi S, Taslimi Z, Ahmadpanah M, Ghaleiha A. Adjustment to diabetes among diabetic patients: the roles of social support and self-efficacy. Avicenna Journal of Neuro Psycho Physiology. 2016;3(1):e37470. doi: 10.17795/ ajnpp-37470.

23. Wang Z, Vang M, Lookadoo K, Tchernev JM, Cooper C. Engaging high-sensation seekers: the dynamic interplay of sensation seeking, message visual-auditory complexity and arousing content. J Commun. 2015;65(1):101-24. doi: 10.1111/jcom.12136.

24. Brooks TL, Harris SK, Thrall JS, Woods ER. Association of adolescent risk behaviors with mental health symptoms in high school students. J Adolesc Health. 2002;31(3):240-6. doi: 10.1016/s1054-139x(02)00385-3.

25. Olchowski AE, Graham JW, Beverly EA, Dupkanick CW. Cigarette smoking, physical activity, and the health status of college students. J Appl Soc Psychol. 2009;39(3):683-706. doi: 10.1111/j.1559-1816.2009.00456.x.

26. Luseno WK, Field SH, Iritani BJ, Odongo FS, Kwaro D, Amek $\mathrm{NO}$, et al. Pathways to depression and poor quality of life among adolescents in western Kenya: role of anticipated HIV stigma, HIV risk perception, and sexual behaviors. AIDS Behav. 2020. doi: 10.1007/s10461-020-02980-5. 